\title{
O Parnasianismo no Brasil: variações sobre um mesmo tema
}

Sergio Alves Peixoto

Universidade Federal de Minas Gerais

Resumo: Este artigo trata da diferença básica entre o parnasianismo francês e o parnasianismo brasileiro, isto é, a presença da subjetividade lírica de nossos autores face aos franceses, principalmente quando se estuda a poética de Olavo Bilac.

Palavras-chave: Parnasianismo francês, Parnasianismo brasileiro, Olavo Bilac.

\begin{abstract}
Um soneto sem defeito é aquele onde se faz entrar o maior número de cortes engenhosos e de epítetos raros, sem uma suspeita de emoção ou de idéia. Como eu lhe objetasse que tal poética deveria produzir obras de uma frieza glacial, ele me lançou um olhar de desdenhosa piedade e me respondeu com um ar solene e hierático: Senhor, o mármore também é frio.
\end{abstract}

\begin{abstract}
Ao estudarmos o Parnasianismo no Brasil, vemos que a "frieza glacial", de que fala Villiers de Lisle-Adam na epígrafe acima, sofreu muito com o sol dos trópicos. Em seu excelente livro, intitulado Parnasianismo brasileiro: entre ressonância e dissonância, ${ }^{2}$ Luís Augusto Fischer nos lembra que se houve influência desse
\end{abstract}

1. In: VINCENT. Les parnassiens, p. 30.

2. FISCHER. Parnasianismo brasileiro: entre ressonância e dissonância. 
"péssimo estilo francês", como o via José Veríssimo já no próprio século XIX, ela se deu em termos bem diferentes da matriz européia.

É verdade, porém, que durante muito tempo a França impregnou a cultura brasileira dos oitocentos, em cuja segunda metade nos tornamos, ou procuramos nos tornar, parnasianos para nos equipararmos a Paris. E como essa segunda metade foi essencialmente uma época de ciência e de filosofia positivistas, tornamo-nos, também, discípulos de Augusto Comte, para quem, no seu Catecismo positivista, o elemento subjetivo deve necessariamente estar submetido ao objetivo. Para Comte, a digna submissão do primeiro ao segundo é verdade essencial e, a partir dela, o homem e o artista deveriam colocar a subjetividade em seu "positivo lugar". Razão, objetividade, impessoalidade, elementos essenciais e inerentes à filosofia de Comte são, na verdade, dados comuns à ciência e à arte desse momento parnasiano-positivista. No Brasil, o crítico Sílvio Romero detectou sintomas de uma poesia que se iniciava buscando eliminar as excessivas lamúrias do Romantismo. Essa poesia, que viria a ser chamada de parnasiana, veio para tentar pôr um freio ao "mau gosto" Romântico, tornando-se algo nobremente formal. Instaura-se, nesse momento, o culto da arte-pela-arte. Téophile Gautier, com seu prefácio ao romance Mlle. de Maupin, faz um verdadeiro manifesto dessa arte que se quer pura, refinada, desinteressada e inútil:

Não, imbecis, não cretinos e idiotas que vós sois, um livro não serve como sopa de gelatina; não é um par de botas sem costura; um soneto não é uma seringa de jato contínuo; um drama não é uma estrada de ferro, todas essas coisas essencialmente civilizantes, fazendo a humanidade marchar pelo caminho do progresso. (...) Não se faz um boné de algodão de uma metonímia, não se calça uma comparação como se ela fosse uma pantufa; não nos podermos servir de uma antítese como de um guarda-chuva; infelizmente não podemos vestir algumas rimas coloridas como se veste um colete. (...) Nada do que é belo é indispensável à vida. (...) O que é verdadeiramente belo não serve para nada; tudo o que é útil é feio, porque é a expressão de uma necessidade, e as necessidades do homem são ignóbeis e repugnantes como sua pobre e uniforme natureza. O lugar mais útil em qualquer casa são as latrinas. ${ }^{3}$

3. In: GERSHMAN; WHITWORTH. Anthologie des préfaces de romans français du XIX siècle, p. 159. 
Nessa arte pura, alheia ao mundo circundante, erudição e poesia passam a andar de mãos dadas, na medida em que ambas são consequência de mentes privilegiadas que buscam afastar-se para longe do cotidiano por meio de uma linguagem rara e impenetrável ao vulgo. Estudo paciente do presente ou do passado e um grande controle das emoções, para não desvirtuar a realidade, eis duas atitudes que se combinariam no poeta parnasiano, tão bem representado pelo chefe dessa escola, Leconte de Lisle. É da seguinte forma que ele apresenta aos leitores seus Poèmes antiques:

Este livro é uma reunião de estudos, um retorno refletido a formas negligenciadas ou pouco conhecidas. Nelas, há poucos traços de emoções pessoais; as paixões e os fatos contemporâneos aí não aparecem. Se bem que a arte possa dar certa medida, um caráter de generalidade a tudo que ela toca, há no testemunho público das angústias do coração e de suas voluptuosidades não menos amargas uma vaidade e uma profanação gratuitas. Por outro lado, por mais vivas que sejam as paixões políticas deste tempo, elas pertencem ao mundo da ação; o trabalho especulativo lhes é estranho. Isso explica a impessoalidade e a neutralidade desses estudos.

Nobre e aristocrata, o poeta Parnasiano, rejeitando a excessiva lamúria que os românticos tanto cultuaram, viu, então, no culto à perfeição do verso, a forma de se atingir esse mundo superior e aristocrático, como nos mostram, ainda, as palavras do mesmo Leconte de Lisle, quando se refere ao poema "Jocelyn", do meigo e agora ridicularizado Lamartine:

Este poema é a revelação completa de uma natureza de espírito que,confesso, me fere e me irrita em todas as minhas fibras sensíveis. Salvo raros momentos plenamente acabados, há nesse gemido contínuo tal ausência de virilidade e de ardor real, esta língua é de tal modo mole, afeminada e incorreta, faltam ao verso tanto músculos, sangue e nervos que é impossível prosseguir sua leitura sem um intolerável mal-estar.

No Brasil, Alberto de Oliveira, nosso primeiro parnasiano, resumiu o ideal dessa poesia plasmada em uma forma bizarramente sonora, puramente feita

4. LISLE. Derniers poèms, p. 215.

5. LISLE. Derniers poèms, p. 254. 
de técnica e artifícios versificatórios em seu famoso texto "O culto da forma na poesia brasileira":

Aquela expressão perfeita, a ciência e o respeito da língua, a repugnância ao emprego de epítetos gastos e não precisos, de imagens que por serem de todos, ficam sem autoria responsável, de termos vagos, sem outro préstimo senão o de enchimento, de cunhas ou rípios, e por sua vez, e por assim dizer, o matiz vocal do ou música variada da frase, com exclusão das monofonias viciosas no verso e na rima; as rimas ricas, de palavras de diversas categorias gramaticais, acostadas às irmãs vulgares ou de uma só classe, como a socorrê-las piedosas, amparando-as em sua pobreza, a elevação, a pureza, a distinção da linguagem poética, tais foram e continuam ser as aspirações, o sonho, o ideal da forma parnasiana. ${ }^{6}$

Em poucas palavras, Alberto de Oliveira resume os principais postulados da nova poesia que agora solidificava seus ideais. Nelas, a constante preocupação com a língua, com a forma, com a técnica do verso; nenhum espaço para as emoções, para os sentimentos. No todo, certa elegância necessária, um distanciamento estudado, uma pose aristocrática de grande artista, tudo bem característico da estética parnasiana lançada por Leconte de Lisle.

Entretanto, se Alberto de Oliveira foi nosso primeiro parnasiano, Olavo Brás Martins dos Guimarães Bilac foi o seu mais famoso representante. Foi ele um dos que mais se afastaram da teoria parnasiana francesa, inclusive, como veremos mais adiante, escrevendo uma paráfrase do decididamente antiparnasiano Baudelaire. Seu mais conhecido poema, por figurar em todos os livros didáticos, é "Profissão de fé". Nele se vê ferido o princípio básico do Parnasianismo: a objetividade, a isenção pessoal. Se dissermos que "Profissão de fé" não contém elementos da grande arte parnasiana, estaríamos mentindo; aí vemos a preocupação com as rimas ricas, com o tom solene e nobre, com a palavra rara em busca de uma rara beleza antiga, com os muitas vezes artificiais enjambements. Entretanto, tudo isso se encontra, no poema, de certo modo subvertido por um poeta essencialmente lírico. A emoção e o entusiasmo do poeta sobrepuja a razão raciocinante, e Bilac deixa que seu eu domine todo o conjunto. Constantemente comparado ao conhecido poema de Gautier, "L'art", publicado em Émaux et camées, o texto de Bilac difere

\footnotetext{
6. In: COUTinho. Caminhos do pensamento crítico, v. 1, p. 594.
} 
bastante do poema do escritor francês. Enquanto Gautier prefere nitidamente o mármore e o bronze para traçar grandes painéis de cenas heróico-épicas da mitologia greco-latina, Bilac tenta se igualar ao cinzelador e ao ourives que trabalham suave e amorosamente materiais delicados. Um outro elemento importantíssimo no poema de Bilac, e totalmente ausente do texto de Gautier, é que o poeta francês se perde na metaforização do poeta como escultor e pintor. No texto de Bilac, não. A preferência por materiais delicados está intimamente associada ao objeto com que o poeta trabalha e ao material em que, amorosamente, cinzelaria seu poema: a pena e o papel. Bilac, prazerosamente, nos fala do ato de escrever e sua poesia nada mais é do que o gozo do estilo. O mais importante, é claro, é o manejo do idioma, o trabalho com o vocábulo. Tudo isso, enretanto, bilaqueanamente vazado em versos em que a emoção predomina. Na verdade, Bilac escreveu poemas tipicamente parnasianos, como os famosos "O incêndio de Roma" e "A sesta de Nero", textos em que se vê claramente a presença dos dogmas do Parnasianismo francês. Poemas descritivos ou narrativos, pomposos, vazados em linguagem afetada, onde o que se procura é demonstrar a capacidade vernacular do poeta. São os "grandes poemas menores" de Bilac, espécie de submissão a preceitos que não se coadunavam com a alma lírica do autor brasileiro, mas que representam bem a escola que pretendeu ser o Parnasianismo no Brasil. Refinados poemas, mas vazios de emoção e da grande poesia que nos prende e nos leva para seus grandes "paraísos artificiais" necessários. Se esses poemas não desmerecem o artífice da língua e da versificação, pouco contribuem para o grande poeta que ele conseguiu ser. Aí estão os dois sonetos citados:

O incêndio de Roma

Raiva o incêndio. A ruir, soltas, desconjuntadas, As muralhas de pedra, o espaço adormecido De eco em eco acordando ao medonho estampido Como a um sopro fatal, rolam esfaceladas.

E os templos, os museus, o Capitólio erguido Em mármor frígio, o Foro, as erectas arcadas Dos aquedutos, tudo as garras inflamadas Do incêndio cingem, tudo esbroa-se partido.

Longe, reverberando o clarão purpurino, Arde em chamas o Tibre e acende-se o horizonte... Impassível, porém, no alto do Palatino, 
Nero, com o manto grego ondeando ao ombro, assoma

Entre os libertos, e ébrio, engrinaldada a fronte,

Lira em punho, celebra a destruição de Roma. ${ }^{7}$

A sesta de Nero

Fulge de luz banhado, esplêndido e suntuoso,

O palácio imperial de pórfiro luzente

E mármor da Lacônia. O teto caprichoso

Mostra, em prata incrustado, o nácar do Oriente.

Nero, no toro ebúrneo estende-se indolente

Gemas em profusão no estrágulo custoso

De ouro bordado vêem-se. O olhar deslumbra, ardente

Da púrpura da Trácia o brilho esplendoroso.

Formosa ancila canta. A aurilavrada lira

Em suas mãos soluça. Os ares perfumando,

Arde a mirra da Arábia em recendente pira.

Formas quebram, dançando, escravas em coréia.

E Nero dorme e sonha, a fronte reclinando

Nos alvos seios nus da lúbrica Popéia.

Um outro grande poeta do momento parnasiano brasileiro, Raimundo Correia, mostrou muito bem o vazio e os prejuízos que o Parnasianismo francês, copiado por muitos no Brasil, trouxe à poesia que se fazia então. Invejando os que não se deixaram subjugar pelos dogmas de Leconte de Liste, Raimundo Correia assim se manifesta:

Como eu invejo isso, eu, devastado completamente pelos prejuízos dessa escola a que chamam parnasiana, cujos produtos aleijados e raquíticos apresentam todos os sintomas da decadência e parecem condenados, de nascença, à morte e ao olvido! Dessa literatura que importamos de Paris, diretamente ou com escala por Lisboa. Literatura tão falsa, postiça e alheia de nossa índole, o que breve resultará, pressinto-o, é uma triste e lamentável esterilidade. Eu sou talvez uma das vítimas desse mal, que

7. BILAC. Poesias, p. 24.

8. BILAC. Poesias, p. 25. 
vai grassando entre nós. Não me atrevo, pois, a censurar ninguém; lastimo profundamente a todos.

Dessa esterilidade, de que fala Raimundo Correia, Bilac soube escapar muito rapidamente. Não durou muito tempo o veio que se pensou ser de ouro puro, mas acabou muitas vezes como mero "ouro de tolo". Isto é, do parnasianismo ortodoxo à francesa, pouco resta na poesia bilaqueana. Nos trópicos não vingou a impassibilidade e o distanciamento emocional. O eu lírico preponderou, como mostram, por exemplo, os famosos sonetos da Via Láctea do poeta carioca. Assim é, que, deixando de lado a frieza marmórea, Bilac se entrega à efusão líricosentimental, como nos mostram os quatro poemas que se seguem, dos mais belos e representativos de sua poética:

Soneto X

Deixa que o olhar do mundo enfim devasse

Teu grande amor que é teu maior segredo!

Que terias perdido, se, mais cedo,

Todo o afeto que entes se mostrasse?

Basta de enganos! Mostra-me sem medo Aos homens, afrontando-os face a face:

Quero que os homens todos, quando eu passe, Invejosos, apontem-me com o dedo.

Olha: não posso mais! Ando tão cheio

Deste amor, que minh'alma se consome

De te exaltar aos olhos do universo...

Ouço em tudo teu nome, em tudo o leio:

$\mathrm{E}$, fatigado de calar teu nome,

Quase o revelo no final de um verso. ${ }^{10}$

9. In: VAL. Vida e obra de Raimundo Correia, p. 213.

10. BILAC. Poesias, p. 50. 


\section{Soneto XIII}

"Ora (direis) ouvir estrelas! Certo

Perdeste o censo!" E eu vos direi, no entanto, Que, para ouvi-las, muita vez desperto

E abro as janelas, pálido de espanto...

E conversamos toda a noite, enquanto A via-láctea, como um pálio aberto, Cintila. E, ao vir do sol, saudoso e em pranto, Inda as procuro pelo céu deserto.

Direis agora: "Tresloucado amigo!

Que conversa com elas? Que sentido

Tem o que dizem, quando estão contigo?"

E eu vos direi: "Amai para entendê-las! Pois só quem ama pode ter ouvido Capaz de ouvir e de entender estrelas". ${ }^{11}$

\section{Soneto XVII}

Por estas noites frias e brumosas

É que melhor se pode amar, querida! Nem uma estrela pálida, perdida

Entre a névoa, abre as pálpebras medrosas...

Mas um perfume cálido de rosas

Corre a face da terra adormecida...

E a névoa cresce, e, em grupos repartida, Enche os ares de sombras vaporosas:

Sombras errantes, corpos nus, ardentes Carnes lascivas... um rumor vibrante De atritos longos e de beijos quentes...

E os céus se estendem, palpitando, cheios Da tépida brancura fulgurante De um turbilhão de braços e de seios. ${ }^{12}$

11. BILAC. Poesias, p. 53.

12. BILAC. Poesias, p. 57. 
Paráfrase de Baudelaire

Assim! Quero sentir sobre a minha cabeça

O peso dessa noite embalsamada e espessa...

Que suave calor, que volúpia divina

As carnes me penetra e os nervos me domina!

Ah! Deixa-me aspirar indefinidamente

Esse aroma sutil, esse perfume ardente!

Deixa-me adormecer envolto em teus cabelos!...

Quero senti-los, quero aspirá-los, sorvê-los,

E neles mergulhar loucamente o meu rosto,

Como quem vem de longe, e, às horas do sol posto,

Acha a um canto da estrada uma nascente pura,

Onde mitiga ansioso a sede que o tortura...

Quero tê-los nas mãos, e agitá-los, cantando,

Como a um lenço, pelo ar saudades espalhando.

Ah! se pudesses ver tudo o que neles vejo!

Meu desvairado amor ! meu insano desejo!...

Teus cabelos contêm uma visão completa:

Largas águas, movendo a superfície inquieta, Cheia de um turbilhão de velas e de mastros,

Sob o claro dossel palpitane dos astros;

Cava-se o mar, rugindo, ao peso dos navios

De todas as nações e todos os feitios,

Desenrolando no alto as flâmulas ao vento,

E recortando o azul do limpo firmamento,

Sob o qual há ume eterna, uma infinita calma.

E prevê meu olhar e pressente minh'alma

Longe, onde, mais profundo e mais azul, se arqueia

O céu, onde há mais luz, e onde a atmosfera, cheia

De aromas, ao repouso e ao divagar convida,

Um país encantado, uma região querida,

Fresca, sorrindo ao sol, entre frutos e flores:

Terra santa da luz, do sonho e dos amores

Terra que nunca vi, terra que não existe,

Mas da qual, entretanto, eu, desterrado e triste,

Sinto no coração, ralado de ansiedade,

Uma saudade eterna, uma fatal saudade!

Minha pátria ideal! Em vão estendo os braços 
Para teu lado! Em vão para teu lado os passos

Movo! Em vão! Nunca mais em teu seio adorado

Poderei repousar meu corpo fatigado...

Nunca mais! Nunca mais!

Sobre a minha cabeça,

Querida! abre essa noite embalsamada e espessa!

Desdobra sobre mim os teus negros cabelos!

Quero, sôfrego e louco, aspirá-los, mordê-los,

E, bêbado de amor, o seu peso sentindo,

Neles dormir envolto e ser feliz dormindo...

Ah! se pudesses ver tudo o que neles vejo!

Meu desvairado amor! Meu insano desejo! $!^{13}$

Se o romance naturalista de Zola conseguiu se adaptar aos trópicos brasileiros, contribuindo para a germinação de romances de peso dentro da literatura brasileira do século XIX, o mesmo não se deu com Parnasianismo, principalmente quando se pensa nos grandes poetas da escola. Alguns atribuem esse fato à alma brasileira, mais afeita à musicalidade e aos sentimentos, mais propensa às expansões líricas e afetivas. Mas isso é uma outra história, a dos temperamentos, a da cultura e a das idéias.

Parnasianism in Brazil: variations about the same theme

Abstract: This article aims to analyse the basic difference between French parnasianism and the Brazilian parnasianism, that is, the presence of a lyric subjetctivity in our authors, especially when considering the poetics of Olavo Bilac.

Keywords: French Paranasianism, Brazilian Parnasianism, Olavo Bilac.

13. BILAC. Poesias, p. 107. 
Belo Horizonte, p. 1-133

$$
\text { Referências }
$$

BILAC, Olavo. Poesias. Rio de Janeiro: Civilização Brasileira, 1977.

COUTINHO, Afrânio. Caminhos do pensamento crítico. Rio de Janeiro: Pallas, 1980.

FISCHER, L. A. Parnasianismo brasileiro: entre ressonância e dissonância. Porto Alegre: EDIPUCRS, 2003.

GERSHMAN, Herbert; WITHWORTH, Herman. Anthologie des préfaces de romans français du XIXe siècle. Paris: Union Générale d'Edition, 1971.

LISLE, Leconte de. Derniers poèmes. Paris: Alphonse Lemerre, [s.d.].

VAL, Waldir Ribeiro do. Vida e obra de Raimundo Correia. Rio de Janeiro, Instituto Nacional do Livro, 1960.

VINCENT, Francis. Les parnassiens. Paris: Beauchesne, 1933. 